Article

\title{
New Conjugates of Polyhydroxysteroids with Long-Chain Fatty Acids from the Deep-Water Far Eastern Starfish Ceramaster patagonicus and Their Anticancer Activity
}

\author{
Timofey V. Malyarenko ${ }^{1,2, *}$, Alla A. Kicha ${ }^{1}$, Olesya S. Malyarenko ${ }^{1} \oplus$, Viktor M. Zakharenko ${ }^{2}$, \\ Ivan P. Kotlyarov ${ }^{2}$, Anatoly I. Kalinovsky ${ }^{1}$, Roman S. Popov ${ }^{1}$, Vasily I. Svetashev ${ }^{3}$ and \\ Natalia V. Ivanchina ${ }^{1}$ \\ 1 G.B. Elyakov Pacific Institute of Bioorganic Chemistry, Far Eastern Branch of the Russian \\ Academy of Sciences, Pr. 100-let Vladivostoku 159, Vladivostok 690022, Russia; \\ kicha@piboc.dvo.ru (A.A.K.); malyarenko.os@gmail.com (O.S.M.); kaaniw@piboc.dvo.ru (A.I.K.); \\ prs_90@mail.ru (R.S.P.); ivanchina@piboc.dvo.ru (N.V.I.) \\ 2 Department of Bioorganic Chemistry and Biotechnology, School of Natural Sciences, \\ Far Eastern Federal University, Sukhanova Str. 8, Vladivostok 690000, Russia; \\ rarf247@gmail.com (V.M.Z.); ivan_1999_19@icloud.com (I.P.K.) \\ 3 A.V. Zhirmunsky National Scientific Center of Marine Biology, Far Eastern Branch of the Russian Academy \\ of Sciences, 17 Palchevsky St., Vladivostok 690041, Russia; vsvetashev@mail.ru \\ * Correspondence: malyarenko-tv@mail.ru; Tel.: +7-423-2312-360; Fax: +7-423-2314-050
}

Received: 27 April 2020; Accepted: 13 May 2020; Published: 15 May 2020

\begin{abstract}
Four new conjugates, esters of polyhydroxysteroids with long-chain fatty acids (1-4), were isolated from the deep-water Far Eastern starfish Ceramaster patagonicus. The structures of 1-4 were established by NMR and ESIMS techniques as well as chemical transformations. Unusual compounds 1-4 contain the same $5 \alpha$-cholestane- $3 \beta, 6 \beta, 15 \alpha, 16 \beta, 26$-pentahydroxysteroidal moiety and differ from each other in the fatty acid units: $5^{\prime} Z, 11^{\prime} Z$-octadecadienoic (1), 11'Z-octadecenoic (2), 5'Z,11'Z-eicosadienoic (3), and 7'Z-eicosenoic (4) acids. Previously, only one such steroid conjugate with a fatty acid was known from starfish. After $72 \mathrm{~h}$ of cell incubation, using MTS assay it was found that the concentrations of compounds $\mathbf{1}, \mathbf{2}$, and 3 that caused 50\% inhibition of growth (IC 50 ) of JB6 Cl41 cells were 81, 40, and $79 \mu \mathrm{M}$, respectively; for MDA-MB-231 cells, $\mathrm{IC}_{50}$ of compounds 1, 2, and 3 were 74, 33, and $73 \mu \mathrm{M}$, respectively; for HCT 116 cells, IC 50 of compounds 1, 2, and 3 were 73, 31, and $71 \mu \mathrm{M}$, respectively. Compound 4 was non-toxic against tested cell lines even in three days of treatment. Compound $2(20 \mu \mathrm{M})$ suppressed colony formation and migration of MDA-MB-231 and HCT 116 cells.
\end{abstract}

Keywords: polyhydroxysteroidal esters; NMR spectra; fatty acids; starfish; Ceramaster patagonicus; cytostatic activity; soft agar assay; wound healing assay

\section{Introduction}

Starfish (Echinodermata, Asteroidea) are a rich source of various secondary metabolites: peptides, fatty acids, polar steroids and their glycosides, carotenoids, quinone pigments, and also sphingolipids and their derivatives [1]. Polar steroid compounds are a major class of starfish secondary metabolites. They are polyhydroxysteroids; glycosides of polyhydroxysteroids (mono-, bi-, and triglycosides); cyclic glycosides; and asterosaponins -oligoglycosides containing $3 \beta, 6 \alpha$-dihydroxysteroidal moieties with the a 9(11)-double bond and an $\mathrm{O}$-sulfate group at C-3 [2-9]. Generally, polyhydroxysteroids have 
from four to nine hydroxyl groups: in the steroid nucleus at positions $3 \beta$ (or more rarely $3 \alpha$ ), $6 \alpha$ (or $\beta$ ), $8,15 \alpha$ (or $\beta$ ), and $16 \beta$ and, more rarely, at positions $4 \beta, 5,7 \alpha$ (or $\beta$ ), and 14; in the side chains at positions 26 and 24 , or simultaneously in the side chain at 25 and 26 positions. The hydroxyl group can also be attached to C-28 or C-29 of the ergostane or stigmastane skeletons, respectively [2-9]. Starfish polyhydroxysteroids often occur in sulfated forms. Usually the sulfate group is located at C-3 or C-15 of the steroidal nucleus or at C-24 or C-26 of the side chain. Sometimes, starfish polyhydroxysteroids and related glycosides are found in the form of conjugates with amino acids. For example, several rare derivatives of starfish polyhydroxysteroids such as polyhydroxysteroid amides conjugated with taurine were isolated from the Arctic starfish Asterias microdiscus [10]. In addition, only one rare steroidal ester of polyhydroxysteroid with long-chain fatty acid, (25S)-5 $\alpha$-cholestane-3 $\beta, 6 \alpha, 7 \alpha, 8,15 \alpha, 16 \beta$-hexaol-26-yl $14^{\prime} Z$-eicosenoate, was isolated from the starfish Asterina pectinifera [11].

Starfish polar steroids have been reported to show a wide spectrum of biological activities, including cytotoxic, antiviral, antibacterial, neuritogenic, and anticancer effects [1-9]. Some starfish polyhydroxylated compounds have been shown to exhibit significant cytotoxicity. For example, certonardosterol $\mathrm{D}_{2}$ revealed cytotoxic effects with effective doses that inhibited a viability of $50 \%$ cells $\left(E_{50}\right)$ against human lung cancer $\mathrm{A} 549\left(\mathrm{ED}_{50}=0.15 \mu \mathrm{g} / \mathrm{mL}\right)$, melanoma SK-MEL-2 $\left(\mathrm{ED}_{50}=0.09 \mu \mathrm{g} / \mathrm{mL}\right)$, ovarian cancer SK-OV-3 $\left(\mathrm{ED}_{50}=0.08 \mu \mathrm{g} / \mathrm{mL}\right), \mathrm{CNS}$ cancer XF498 $\left(\mathrm{ED}_{50}=0.07 \mu \mathrm{g} / \mathrm{mL}\right)$, and colon cancer HCT15 $\left(\mathrm{ED}_{50}=0.01 \mu \mathrm{g} / \mathrm{mL}\right)$ cell lines [12]. However, (25S)-5 $\alpha$-cholestane-3 $\beta, 6 \alpha, 7 \alpha, 8,15 \alpha, 16 \beta$-hexaol-26-yl 14'Z-eicosenoate did not possess inhibitory activity against herpes simplex virus type 1 (HSV-1) and human liver carcinoma HepG2 cells in vitro [11].

Herein, we report the results of the structural elucidation of four new polyhydroxysteroidal esters (1-4) with fatty acids from the methanol chloroform ethanolic extract of the deep-water Far Eastern starfish Ceramaster patagonicus collected at the Sea of Okhotsk near Iturup Island. We examined the cytotoxic and cytostatic activities of 1-4 on mouse normal epidermal, human breast cancer, and colorectal carcinoma cells. In addition, the effects of these compounds on the colony formation and migration of human breast cancer and colorectal carcinoma cells were investigated using soft agar and wound healing assays.

\section{Results and Discussion}

\subsection{The Isolation and Structure Elucidation of Compounds 1-4 from C. patagonicus}

The concentrated methanol chloroform ethanolic extract of $C$. patagonicus was partitioned between $\mathrm{H}_{2} \mathrm{O}$ and $\mathrm{AcOEt} / \mathrm{BuOH}$, and the organic layer was washed with cold acetone. The acetone-soluble part was subjected to separation by chromatography on silica gel column followed by HPLC on semi-preparative Diasfer-110-C18 column to obtain four new polyhydroxysteroidal compounds: (25S)-5 $\alpha$-cholestane-3 $\beta, 6 \beta, 15 \alpha, 16 \beta$-tetraol-26-yl 5'Z,11'Z-octadecadienoate (1), (25S)-5 $\alpha$-cholestane$3 \beta, 6 \beta, 15 \alpha, 16 \beta$-tetraol-26-yl 11'Z-octadecenoate (2), (25S)-5 $\alpha$-cholestane-3 $\beta, 6 \beta, 15 \alpha, 16 \beta$-tetraol-26-yl $5^{\prime} Z, 11^{\prime} Z$-eicosadienoate (3), and (25S)-5 $\alpha$-cholestane- $3 \beta, 6 \beta, 15 \alpha, 16 \beta$-tetraol-26-yl 7' Z-eicosenoate (4) (Figure 1).

The IR spectrum of compound 1 showed the presence of hydroxyl $\left(3504 \mathrm{~cm}^{-1}\right)$, ester carbonyl $\left(1723 \mathrm{~cm}^{-1}\right)$, and olefinic $\left(1602 \mathrm{~cm}^{-1}\right)$ groups. The molecular formula of compound 1 was determined to be $\mathrm{C}_{45} \mathrm{H}_{78} \mathrm{O}_{6}$ from the $[\mathrm{M}+\mathrm{Na}]^{+}$sodiated adduct ion peak at $m / z 737.5695$ in the $(+)$ HRESIMS, the $[(\mathrm{M}-\mathrm{H})+\mathrm{AcOH}]^{-}$ion peak at $m / z$ 773.5934, and the $[\mathrm{M}-\mathrm{H}]^{-}$deprotonated ion peak at $m / z$ 713.5726 in the (-)HRESIMS (Figures S1 and S2). The ${ }^{1} \mathrm{H}$ - and ${ }^{13} \mathrm{C}-\mathrm{NMR}$ spectroscopic data belonging to the tetracyclic moiety of $\mathbf{1}$ showed the resonances of protons and carbons of two angular methyls, $\mathrm{CH}_{3}-18$ and $\mathrm{CH}_{3}-19\left(\delta_{\mathrm{H}} 1.27 \mathrm{~s}, 1.47 \mathrm{~s} ; \delta_{\mathrm{C}} 14.9,16.2\right)$, and four oxygenated methines, $\mathrm{HC}-3\left(\delta_{\mathrm{H}} 3.99\right.$ $\left.\mathrm{m} ; \delta_{\mathrm{C}} 71.1\right), \mathrm{HC}-6\left(\delta_{\mathrm{H}} 4.15 \mathrm{brs} ; \delta_{\mathrm{C}} 71.2\right), \mathrm{HC}-15\left(\delta_{\mathrm{H}} 4.40 \mathrm{brd}(J=10.0) ; \delta_{\mathrm{C}} 84.7\right)$, and HC-16 $\left(\delta_{\mathrm{H}} 4.66\right.$ brd $\left.(J=7.3) ; \delta_{\mathrm{C}} 82.2\right)$ (Table 1, Figures S4-S12). The NMR spectra of steroidal side chain indicated the existence of two secondary methyls, $\mathrm{CH}_{3}-21\left(\delta_{\mathrm{H}} 1.13 \mathrm{~d}(J=6.8) ; \delta_{\mathrm{C}} 18.3\right)$ and $\mathrm{CH}_{3}-27\left(\delta_{\mathrm{H}} 0.94 \mathrm{~d}(J=6.8)\right.$; $\left.\delta_{\mathrm{C}} 17.0\right)$, and one oxygenated methylene, $\mathrm{H}_{2} \mathrm{C}-26\left(\delta_{\mathrm{H}} 4.11 \mathrm{dd}(J=10.6,5.4), 3.96 \mathrm{dd}(J=10.6,6.8)\right.$; 
$\delta_{\mathrm{C}} 69.1$ ) (Table 1, Figures S4-S12). The ${ }^{1} \mathrm{H}^{-1} \mathrm{H}$ COSY and HSQC correlations attributable to steroidal moiety revealed the corresponding sequences of protons at $\mathrm{C}-1$ to $\mathrm{C}-8$; $\mathrm{C}-8$ to $\mathrm{C}-12$ through $\mathrm{C}-9$ and C-11; C-8 to C-17 through C-14; C-17 to C-21, and C-20 to the end of the side chain (Figure 2A, Figures S13-S16). The key HMBC cross-peaks, such as H-1/C-10, C-19; H-4/C-5, C-6; H-7/C-8; H-14/C-7, C-8, C-13, C-15, C-18; H-17/C-13, C-20; H $3-18 / C-12, C-13, C-14, C-17 ; \mathrm{H}_{3}-19 / \mathrm{C}-1, \mathrm{C}-5, \mathrm{C}-9$, C-10; $\mathrm{H}_{3}-21 / \mathrm{C}-17$, $\mathrm{C}-20, \mathrm{C}-22 ; \mathrm{H}_{2}-26 / \mathrm{C}-24, \mathrm{C}-25, \mathrm{C}-27$; and $\mathrm{H}_{3}-27 / \mathrm{C}-24, \mathrm{C}-25, \mathrm{C}-26$ confirmed the overall structure of the steroidal part of $\mathbf{1}$ (Figure 2A, Figures S17 and S18).

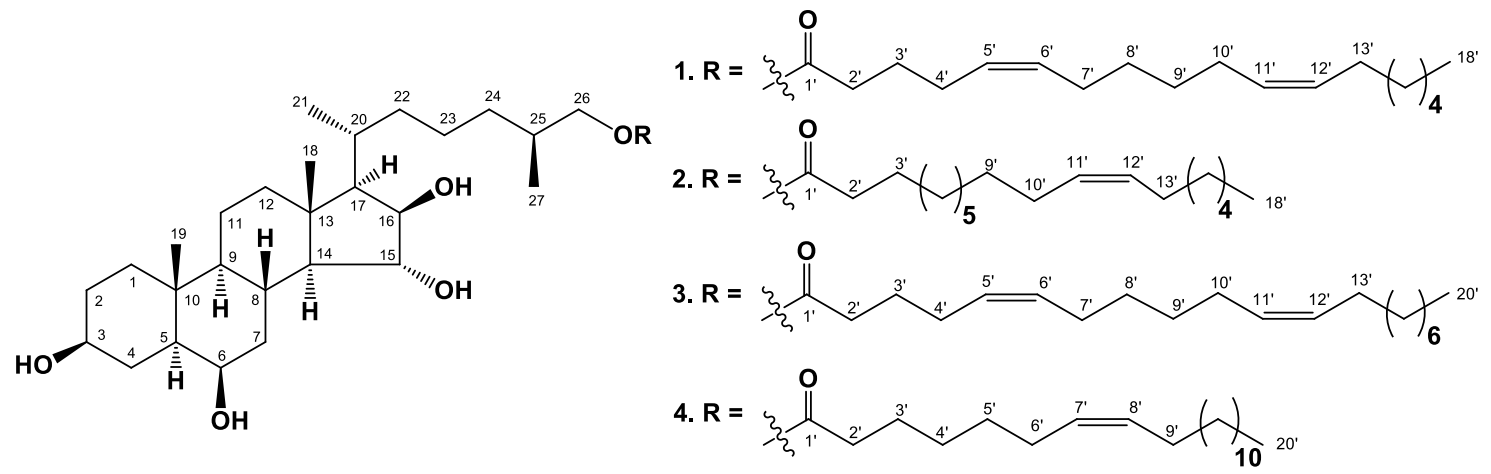

Figure 1. The structures of compounds 1-4 isolated from C. patagonicus.

Table 1. ${ }^{1} \mathrm{H}-(700.13 \mathrm{MHz})$ and ${ }^{13} \mathrm{C}-(176.04 \mathrm{MHz})$ NMR chemical shifts of the steroidal moiety of 1-4 in $\mathrm{C}_{5} \mathrm{D}_{5} \mathrm{~N}$ at $30^{\circ} \mathrm{C}$, with $\delta$ in ppm and $J$ values in $\mathrm{Hz}$.

\begin{tabular}{|c|c|c|c|c|c|}
\hline Position & $\delta_{\mathrm{H}}$ & $\delta_{\mathrm{C}}$ & Position & $\delta_{H}$ & $\delta_{\mathrm{C}}$ \\
\hline 1 & $\begin{array}{c}1.76 \mathrm{dt}(11.4,3.5) \\
1.10 \mathrm{~m}\end{array}$ & 39.1 & 15 & 4.40 brd (10.0) & 84.7 \\
\hline 2 & $\begin{array}{l}2.13 \mathrm{~m} \\
1.86 \mathrm{~m}\end{array}$ & 32.5 & 16 & 4.66 brd (7.3) & 82.2 \\
\hline 3 & $3.99 \mathrm{~m}$ & 71.1 & 17 & $1.55 \mathrm{dd}(11.1,7.3)$ & 59.3 \\
\hline 4 & $\begin{array}{c}2.45 \mathrm{~m} \\
2.04 \mathrm{brd}(12.2)\end{array}$ & 37.0 & 18 & $1.27 \mathrm{~s}$ & 14.9 \\
\hline 5 & $1.35 \mathrm{~m}$ & 48.3 & 19 & $1.47 \mathrm{~s}$ & 16.2 \\
\hline 6 & 4.15 brd (2.6) & 71.2 & 20 & $2.35 \mathrm{~m}$ & 30.0 \\
\hline 7 & $\begin{array}{c}2.95 \mathrm{dt}(14.2,3.5) \\
1.82 \mathrm{~m}\end{array}$ & 41.2 & 21 & $1.13 \mathrm{~d}(6.8)$ & 18.3 \\
\hline 8 & $2.55 \mathrm{qd}(11.1,3.5)$ & 30.8 & 22 & $\begin{array}{l}1.92 \mathrm{~m} \\
1.28 \mathrm{~m}\end{array}$ & 36.4 \\
\hline 9 & $0.96 \mathrm{~m}$ & 54.9 & 23 & $\begin{array}{l}1.60 \mathrm{~m} \\
1.39 \mathrm{~m}\end{array}$ & 23.9 \\
\hline 10 & - & 36.0 & 24 & $\begin{array}{l}1.41 \mathrm{~m} \\
1.17 \mathrm{~m}\end{array}$ & 34.0 \\
\hline 11 & $\begin{array}{l}1.64 \mathrm{~m} \\
1.59 \mathrm{~m}\end{array}$ & 21.2 & 25 & $1.82 \mathrm{~m}$ & 32.8 \\
\hline 12 & $\begin{array}{l}2.10 \mathrm{~m} \\
1.36 \mathrm{~m}\end{array}$ & 41.1 & 26 & $\begin{array}{l}4.11 \mathrm{dd}(10.6,5.4) \\
3.96 \mathrm{dd}(10.6,6.8)\end{array}$ & 69.1 \\
\hline 13 & - & 43.9 & 27 & $0.94 \mathrm{~d}(6.8)$ & 17.0 \\
\hline 14 & $1.45 \mathrm{t}(10.4)$ & 61.0 & & & \\
\hline
\end{tabular}

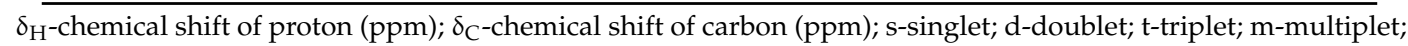
brd-broad doublet; dd-doublet of doublets; dt-doublet of triplets; qd-quartet of doublets. 


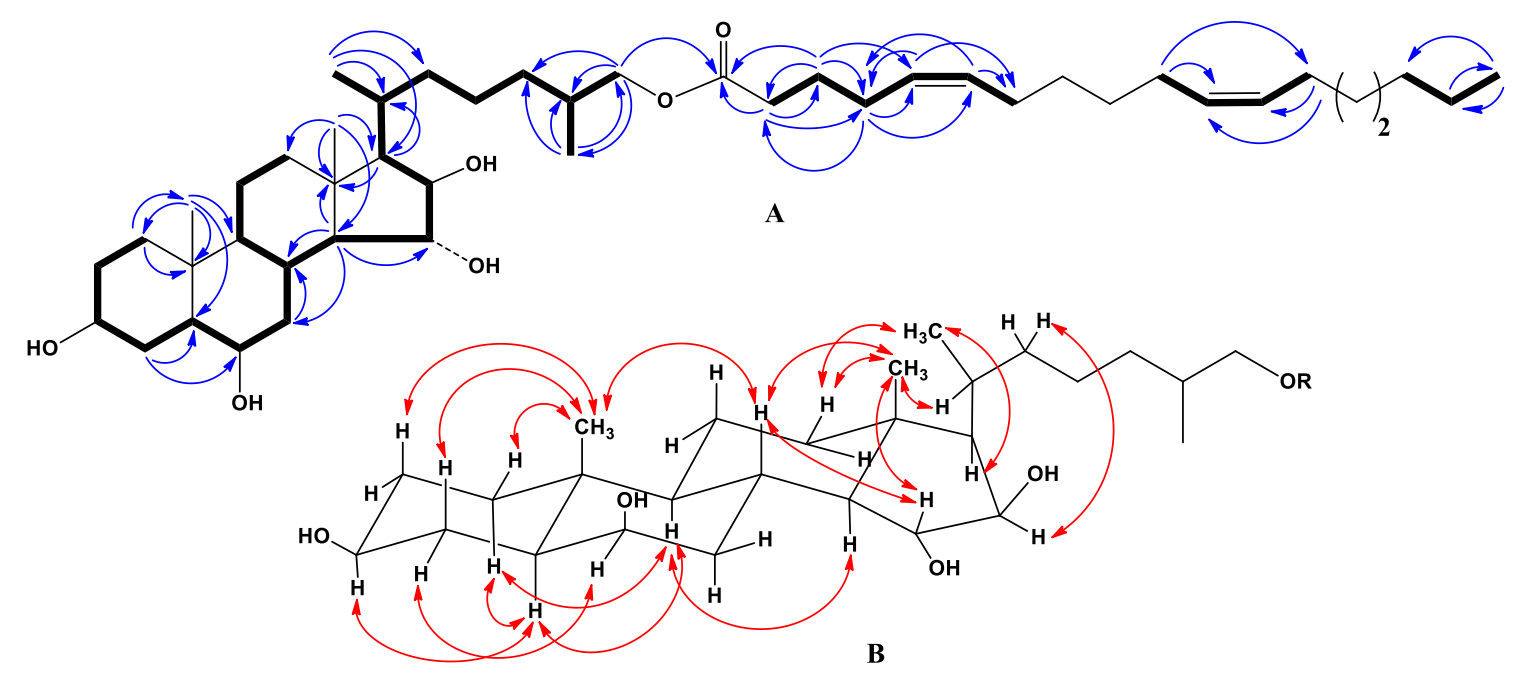

Figure 2. (A) ${ }^{1} \mathrm{H}_{-}{ }^{1} \mathrm{H}$ COSY and key HMBC correlations for compound 1. (B) Key ROESY correlations of steroidal moiety for compounds $\mathbf{1}-\mathbf{4}$.

The key ROESY cross-peaks showed the common $5 \alpha / 9 \alpha / 10 \beta / 13 \beta$ stereochemistry of the steroidal nucleus, $3 \beta, 6 \beta, 15 \alpha, 16 \beta$-configurations of oxygenated substituents and 26-hydroxycholestane side chain in 1 (Figure 2B, Figures S19 and S20). The 20R-configuration was assumed on the basis of ROESY correlations of $\mathrm{H}_{3}-18 / \mathrm{H}-20, \mathrm{H}_{\beta}-16 / \mathrm{H}-22$, and $\mathrm{H}_{3}-21 / \mathrm{H}_{\beta}-12$ (Figure $2 \mathrm{~B}$, Figures S19 and S20). ${ }^{1} \mathrm{H}$ - and ${ }^{13} \mathrm{C}-\mathrm{NMR}$ data of the steroidal part of compound 1 were practically identical to those

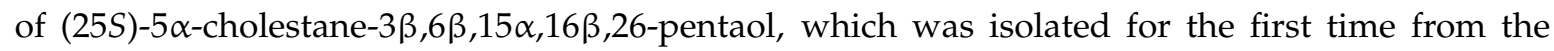
starfish Hacelia attenuata [13] and later from the starfish C. patagonicus [14], which confirmed the identity of the steroid parts of these compounds and indicated the 25S-configuration of the side chain of $\mathbf{1}$. Based on these data, the steroidal moiety of $\mathbf{1}$ was determined as $(20 R, 25 S)-5 \alpha-$ cholestane-3 $\beta, 6 \beta, 15 \alpha, 16 \beta, 26$-pentaol.

In addition, the ${ }^{1} \mathrm{H}$ - and ${ }^{13} \mathrm{C}-\mathrm{NMR}$ spectra of compound $\mathbf{1}$ indicated the presence of one primary methyl, $\mathrm{CH}_{3}-18^{\prime}\left(\delta_{\mathrm{H}} 0.88 \mathrm{t}(J=6.9) ; \delta_{\mathrm{C}} 14.0\right)$; four olefinic methines, HC-5' $\left(\delta_{\mathrm{H}} 5.44 \mathrm{~m} ; \delta_{\mathrm{C}} 128.9\right), \mathrm{HC}-6^{\prime}$ $\left(\delta_{\mathrm{H}} 5.51 \mathrm{~m} ; \delta_{\mathrm{C}} 130.9\right), \mathrm{HC}-11^{\prime}\left(\delta_{\mathrm{H}} 5.48 \mathrm{~m} ; \delta_{\mathrm{C}} 129.8\right)$, and $\mathrm{HC}-12^{\prime}\left(\delta_{\mathrm{H}} 5.49 \mathrm{~m} ; \delta_{\mathrm{C}} 130.1\right)$; two characteristic allyl methylenes, $\mathrm{H}_{2} \mathrm{C}-4^{\prime}\left(\delta_{\mathrm{H}} 2.17 \mathrm{~m} ; \delta_{\mathrm{C}} 26.7\right)$ and $\mathrm{H}_{2} \mathrm{C}-7^{\prime}\left(\delta_{\mathrm{H}} 2.10 \mathrm{~m} ; \delta_{\mathrm{C}} 27.4\right)$; one ester carbonyl $\left(\delta_{\mathrm{C}} 173.3\right)$; and one characteristic methylene, $\mathrm{H}_{2} \mathrm{C}-2^{\prime}\left(\delta_{\mathrm{H}} 2.43 \mathrm{t}(J=7.4) ; \delta_{\mathrm{C}} 33.7\right)$, located at the $\alpha$-position from ester carbonyl group (Table 2, Figures S4-S12). The (-)ESIMS/MS of the ion $[\mathrm{M}-\mathrm{H}]^{-}$at $m / z 713$ contained the fragment ion peaks at $m / z 449\left[\mathrm{C}_{27} \mathrm{H}_{45} \mathrm{O}_{5}\right]^{-}$, corresponding to the loss of long-chain fatty acid residue, and at $m / z 279\left[\mathrm{C}_{18} \mathrm{H}_{31} \mathrm{O}_{2}\right]^{-}$, corresponding to the loss of steroidal moiety. The ${ }^{1} \mathrm{H}^{-}{ }^{1} \mathrm{H}$ COSY and HSQC correlations attributable to fatty acid unit revealed the corresponding sequences

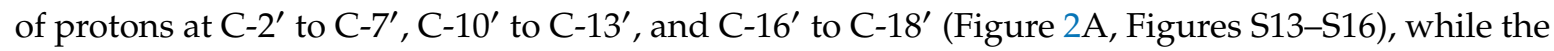

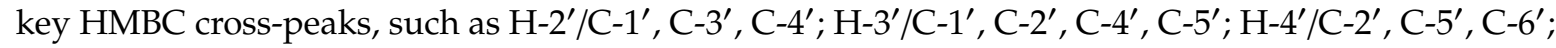
$\mathrm{H}-5^{\prime} / \mathrm{C}-4^{\prime}, \mathrm{C}-7^{\prime}$; and H-6 $/ \mathrm{C}-4^{\prime}, \mathrm{C}-7^{\prime}$, confirmed the localization of $\Delta^{5(6)}$-double bound in the fatty acid unit of 1 (Figure 2A, Figures S17 and S18). The geometry of the double bond in the long-chain fatty acids can be determined on the basis of the ${ }^{13} \mathrm{C}-\mathrm{NMR}$ chemical shift of the methylene carbon adjacent to the olefinic carbon $\left(\delta_{\mathrm{C}} \approx 27\right.$ for $(Z)$ isomers and $\delta_{\mathrm{C}} \approx 32$ for $(E)$ isomers). ${ }^{13} \mathrm{C}-\mathrm{NMR}$ spectrum of compound 1 indicated the presence of four characteristic allyl carbons: C-4' $\left(\delta_{\mathrm{C}} 26.7\right), \mathrm{C}-7^{\prime}\left(\delta_{\mathrm{C}} 27.4\right)$, $\mathrm{C}-10^{\prime}\left(\delta_{\mathrm{C}} 27.4\right)$, and $\mathrm{C}-13^{\prime}\left(\delta_{\mathrm{C}} 27.1\right)$. Thus, the olefin groups in 1 were determined to have cis $(Z)$ geometry. Compound $\mathbf{1}$ was methanolyzed with methanolic hydrochloric acid to give the fatty acid methyl esters (FAME-1) of 1. Additionally, 4,4-dimethyloxazoline derivatives (DMOXs-1) of fatty acids of compound 1 were prepared from FAME-1 according to the procedure described previously [15]. This method allows for determining double bond in polyunsaturated fatty acids. Fatty acids were identified by equivalent chain length (ECL) values in GC analysis and mass spectra of FAME-1 and DMOXs-1 derivatives in GC-MS [15,16]. GC-MS analysis showed the existence of one major component, 
which was characterized as methyl $5^{\prime} Z, 11^{\prime} Z$-octadecadienoate. Minor components and their percentage are shown in Table 3. On the basis of all the above-mentioned data, the structure of $\mathbf{1}$ was determined to be (25S)-5 $\alpha$-cholestane-3 $\beta, 6 \beta, 15 \alpha, 16 \beta$-tetraol-26-yl 5' Z,11'Z-octadecadienoate. It should be noted that NMR, MS, TLC, and HPLC analyses indicated the homogeneity of compounds 1-4; however, GLC-MS analysis of methyl ester of fatty acids 1-4 showed the presence of other fatty acids.

Table 2. ${ }^{1} \mathrm{H}-(700.13 \mathrm{MHz})$ and ${ }^{13} \mathrm{C}-(176.04 \mathrm{MHz}) \mathrm{NMR}$ chemical shifts of the fatty acid units of $\mathbf{1}-\mathbf{4}$ in $\mathrm{C}_{5} \mathrm{D}_{5} \mathrm{~N}$ at $30{ }^{\circ} \mathrm{C}$, with $\delta$ in ppm and $J$ values in $\mathrm{Hz}$.

\begin{tabular}{|c|c|c|c|c|c|c|c|c|}
\hline \multirow{2}{*}{ Position } & \multicolumn{2}{|c|}{1} & \multicolumn{2}{|c|}{2} & \multicolumn{2}{|c|}{3} & \multicolumn{2}{|c|}{4} \\
\hline & $\delta_{\mathbf{H}}$ & $\delta_{\mathrm{C}}$ & $\delta_{\mathbf{H}}$ & $\delta_{\mathrm{C}}$ & $\delta_{\mathrm{H}}$ & $\delta_{\mathrm{C}}$ & $\delta_{\mathrm{H}}$ & $\delta_{\mathrm{C}}$ \\
\hline $1^{\prime}$ & - & 173.3 & - & 173.3 & - & 173.1 & - & 173.3 \\
\hline $2^{\prime}$ & $2.43 \mathrm{t}(7.4)$ & 33.7 & $2.40 \mathrm{t}(7.5)$ & 34.3 & $2.43 \mathrm{t}(7.2)$ & 33.6 & $2.40 \mathrm{t}(7.5)$ & 34.2 \\
\hline $3^{\prime}$ & $1.80 \mathrm{~m}$ & 25.2 & $1.70 \mathrm{~m}$ & 25.1 & $1.80 \mathrm{~m}$ & 25.2 & $1.71 \mathrm{~m}$ & 25.1 \\
\hline $4^{\prime}$ & $2.17 \mathrm{~m}$ & 26.7 & & & $2.17 \mathrm{q}(7.2)$ & 26.7 & & \\
\hline $5^{\prime}$ & $5.44 \mathrm{~m}$ & 128.9 & & & $5.46 \mathrm{~m}$ & 128.9 & & \\
\hline $6^{\prime}$ & $5.51 \mathrm{~m}$ & 130.9 & & & $5.51 \mathrm{~m}$ & 130.9 & $2.11 \mathrm{~m}$ & 27.3 \\
\hline $7^{\prime}$ & $2.10 \mathrm{~m}$ & 27.4 & & & $2.10 \mathrm{~m}$ & 27.4 & $5.50 \mathrm{~m}$ & 130.2 \\
\hline $10^{\prime}$ & $2.11 \mathrm{~m}$ & 27.4 & $2.11 \mathrm{~m}$ & 27.3 & $2.11 \mathrm{~m}$ & 27.4 & $5.48 \mathrm{~m}$ & 129.7 \\
\hline $11^{\prime}$ & $5.48 \mathrm{~m}$ & 129.8 & $5.49 \mathrm{~m}$ & 130.0 & $5.49 \mathrm{~m}$ & 129.8 & $2.11 \mathrm{~m}$ & 27.1 \\
\hline $12^{\prime}$ & $5.49 \mathrm{~m}$ & 130.1 & $5.49 \mathrm{~m}$ & 130.0 & $5.50 \mathrm{~m}$ & 130.1 & & \\
\hline $13^{\prime}$ & $2.11 \mathrm{~m}$ & 27.1 & $2.11 \mathrm{~m}$ & 27.1 & $2.11 \mathrm{~m}$ & 27.1 & & \\
\hline $16^{\prime}$ or $18^{\prime}$ & $1.25 \mathrm{~m}$ & 31.7 & $1.25 \mathrm{~m}$ & 31.8 & $1.25 \mathrm{~m}$ & 31.9 & $1.25 \mathrm{~m}$ & 31.8 \\
\hline $17^{\prime}$ or $19^{\prime}$ & $1.28 \mathrm{~m}$ & 22.7 & $1.28 \mathrm{~m}$ & 22.8 & $1.28 \mathrm{~m}$ & 22.7 & $1.28 \mathrm{~m}$ & 22.8 \\
\hline $18^{\prime}$ or $20^{\prime}$ & $0.88 \mathrm{t}(6.9)$ & 14.0 & 0.87 t (6.9) & 14.0 & $0.88 \mathrm{t}(7.0)$ & 14.0 & $0.89 \mathrm{t}(6.9)$ & 14.0 \\
\hline
\end{tabular}

Table 3. Fatty acid composition of compounds 1-4 based on GC-MS analysis.

\begin{tabular}{ccccc}
\hline \multirow{2}{*}{ Fatty Acids } & \multicolumn{4}{c}{ Content, \% } \\
\cline { 2 - 5 } & $\mathbf{1}$ & $\mathbf{2}$ & $\mathbf{3}$ & $\mathbf{4}$ \\
\hline $16: 0$ & 14.91 & 9.36 & 11.83 & 5.88 \\
\hline$\Delta^{7}-16: 1$ & 5.11 & 0.75 & 5.06 & 1.07 \\
\hline $18: 0$ & 11.23 & 8.92 & 8.13 & 8.03 \\
\hline$\Delta^{5}-18: 1$ & 1.62 & 4.62 & 17.05 & 0.57 \\
\hline$\Delta^{9}-18: 1$ & 5.97 & 6.53 & 6.65 & 4.83 \\
\hline$\Delta^{11}-18: 1$ & 4.06 & $\mathbf{5 1 . 1 6}$ & 3.92 & 2.05 \\
\hline$\Delta^{5,11}-18: 2$ & 53.31 & & 3.73 & 6.14 \\
\hline$\Delta^{7}-20: 1$ & & 8.86 & 3.50 & $\mathbf{6 6 . 6 7}$ \\
\hline$\Delta^{9}-20: 1$ & & & 0.63 & 3.88 \\
\hline$\Delta^{5,11}-20: 2$ & 3.78 & 9.79 & 39.51 & 0.87 \\
\hline Total & 100.00 & 100.00 & 100.00 & 100.00 \\
\hline
\end{tabular}

The IR spectrum of compound 2 showed the presence of hydroxyl $\left(3504 \mathrm{~cm}^{-1}\right)$, ester carbonyl $\left(1723 \mathrm{~cm}^{-1}\right)$, and olefinic $\left(1602 \mathrm{~cm}^{-1}\right)$ groups. The molecular formula of compound 2 was determined to be $\mathrm{C}_{45} \mathrm{H}_{80} \mathrm{O}_{6}$ from the $[\mathrm{M}+\mathrm{Na}]^{+}$sodiated adduct ion peak at $m / z 739.5852$ in the (+)HRESIMS, the $[(\mathrm{M}-\mathrm{H})+\mathrm{AcOH}]^{-}$ion peak at $m / z$ 775.6096, and the $[\mathrm{M}-\mathrm{H}]^{-}$deprotonated ion peak at $m / z$ 715.5889 in the (-)HRESIMS (Figures S21 and S22). The comparison of the molecular masses of 1 and 2 showed that the difference between $\mathbf{1}$ and $\mathbf{2}$ is 2 atomic mass units (amu). The comparison of ${ }^{1} \mathrm{H}-$ and 
${ }^{13} \mathrm{C}-\mathrm{NMR}$ spectra and application of extensive 2D NMR analysis of compounds $\mathbf{1}$ and $\mathbf{2}-\mathbf{4}$ exhibited that steroidal moieties of 2-4 are identical to that of compound 1, while long-chain fatty acid residues of 1-4 differ from each other by the length of the hydrocarbon chains and the number and positions of double bonds (Figure 1, Tables 1 and 2).

The ${ }^{1} \mathrm{H}$ - and ${ }^{13} \mathrm{C}-\mathrm{NMR}$ spectra of fatty acid residue of compound 2 indicated the existence of one primary methyl, $\mathrm{CH}_{3}-18^{\prime}\left(\delta_{\mathrm{H}} 0.87 \mathrm{t}(J=6.9) ; \delta_{\mathrm{C}} 14.0\right)$; two olefinic methines, $\mathrm{HC}-11^{\prime}$ and HC-12' $\left(2 \mathrm{H}\right.$, each $\left.\delta_{\mathrm{H}} 5.49 \mathrm{~m} ; \delta_{\mathrm{C}} 130.0\right)$; two characteristic allyl methylenes, $\mathrm{H}_{2} \mathrm{C}-10^{\prime}\left(\delta_{\mathrm{H}} 2.11 \mathrm{~m} ; \delta_{\mathrm{C}} 27.3\right)$ and $\mathrm{H}_{2} \mathrm{C}-13^{\prime}\left(\delta_{\mathrm{H}} 2.11 \mathrm{~m} ; \delta_{\mathrm{C}} 27.1\right)$; one ester carbonyl $\left(\delta_{\mathrm{C}} 173.3\right)$; and one characteristic methylene, $\mathrm{H}_{2} \mathrm{C}-2^{\prime}$ $\left(\delta_{\mathrm{H}} 2.40 \mathrm{t}(J=7.5) ; \delta_{\mathrm{C}} 34.3\right)$, located at the $\alpha$-position from ester carbonyl group (Table 2, Figures S24 and S25). The (-)ESIMS/MS of the ion $[\mathrm{M}-\mathrm{H}]^{-}$at $\mathrm{m} / \mathrm{z} 715$ contained the fragment ion peaks at $m / z 449\left[\mathrm{C}_{27} \mathrm{H}_{45} \mathrm{O}_{5}\right]^{-}$, corresponding to the loss of long-chain fatty acid, and $m / z 281\left[\mathrm{C}_{18} \mathrm{H}_{33} \mathrm{O}_{2}\right]^{-}$, corresponding to the loss of steroidal moiety. Difference of 2 amu between fragment ion peaks at $m / z 281\left[\mathrm{C}_{18} \mathrm{H}_{33} \mathrm{O}_{2}\right]^{-}$and $279\left[\mathrm{C}_{18} \mathrm{H}_{31} \mathrm{O}_{2}\right]^{-}$in the (-)ESIMS/MS mass spectra of compounds 2 and 1 indicated the absence of one double bond in the fatty acid moiety of compound 2 compared to $\mathbf{1}$ (Figures S3 and S23). The comparison of ${ }^{1} \mathrm{H}$ - and ${ }^{13} \mathrm{C}-\mathrm{NMR}$ data of $\mathbf{2}$ and $\mathbf{1}$ also confirmed this conclusion (Table 2, Figures S4-S12 and S24, S25). The cis (Z) geometry of the double bond in the long-chain fatty acid moiety of 2 can be determined on the basis of the ${ }^{13} \mathrm{C}-\mathrm{NMR}$ chemical shift of the C-10' $\left(\delta_{\mathrm{C}} 27.3\right)$ and C-13' $\left(\delta_{\mathrm{C}} 27.1\right)$.

Fatty acid units in 2 were identified by ECL values of fatty acids in GC analysis and mass spectra of FAME-2 and DMOXs-2 derivatives in GC-MS [16] similar to compound 1. GC-MS analysis showed the existence of one major component, which was identified as methyl $11^{\prime} Z$-octadecenoate. Minor components and their percentage are shown in Table 3. Thereby, the structure of 2 was established to be (25S)- $5 \alpha$-cholestane-3 $\beta, 6 \beta, 15 \alpha, 16 \beta$-tetraol-26-yl 11'Z Z-octadecenoate.

The IR spectrum of compound 3 showed the presence of hydroxyl $\left(3510 \mathrm{~cm}^{-1}\right)$, ester carbonyl $\left(1723 \mathrm{~cm}^{-1}\right)$, and olefinic $\left(1603 \mathrm{~cm}^{-1}\right)$ groups. The molecular formula of compound 3 was determined to be $\mathrm{C}_{47} \mathrm{H}_{82} \mathrm{O}_{6}$ from the $[\mathrm{M}+\mathrm{Na}]^{+}$sodiated adduct ion peak at $m / z 765.6008$ in the $(+)$ HRESIMS, the $[(\mathrm{M}-\mathrm{H})+\mathrm{AcOH}]^{-}$ion peak at $m / z$ 801.6254, and the $[\mathrm{M}-\mathrm{H}]^{-}$deprotonated ion peak at $\mathrm{m} / \mathrm{z}$ 741.6044 in the (-)HRESIMS (Figures S30 and S31). The comparison of the molecular masses of 1 and 3 showed that the difference between them is $28 \mathrm{amu}$. At the same time, the ${ }^{1} \mathrm{H}$ - and ${ }^{13} \mathrm{C}-\mathrm{NMR}$ spectra of compounds 1 and 3 were almost identical (Tables 1 and 2, Figures S4-S12 and S33, S34). The (-)ESIMS/MS of the ion $[\mathrm{M}-\mathrm{H}]^{-}$at $m / z 741$ contained the fragment ion peaks at $m / z 449\left[\mathrm{C}_{27} \mathrm{H}_{45} \mathrm{O}_{5}\right]^{-}$, corresponding to the loss of long-chain fatty acid, and $m / z 307\left[\mathrm{C}_{20} \mathrm{H}_{35} \mathrm{O}_{2}\right]^{-}$, corresponding to the loss of steroidal moiety. Fatty acid units in 3 were identified by ECL values of fatty acids in GC analysis and mass spectra of FAME-3 and DMOXs-3 derivatives in GC-MS $[15,16]$. GC-MS analysis showed the existence of one major component, which was identified as methyl $5^{\prime} Z, 11^{\prime} Z$-eicosadienoate. Accordingly, the structure of 3 was determined to be (25S)-5 $\alpha$-cholestane- $3 \beta, 6 \beta, 15 \alpha, 16 \beta$-tetraol-26-yl $5^{\prime} Z, 11^{\prime} Z$-eicosadienoate. The cis $(Z)$ geometry of the double bond in the long-chain fatty acid moiety of 3 can be determined on the basis of the ${ }^{13} C-N M R$ chemical shift of the C-10' $\left(\delta_{C} 27.3\right)$ and C-13' $\left(\delta_{C} 27.1\right)$.

The IR spectrum of compound 4 showed the presence of hydroxyl $\left(3515 \mathrm{~cm}^{-1}\right)$, ester carbonyl $\left(1723 \mathrm{~cm}^{-1}\right)$, and olefinic $\left(1602 \mathrm{~cm}^{-1}\right)$ groups. The molecular formula of compound 4 was determined to be $\mathrm{C}_{47} \mathrm{H}_{84} \mathrm{O}_{6}$ from the $[\mathrm{M}+\mathrm{Na}]^{+}$sodiated adduct ion peak at $m / z 767.6157$ in the $(+)$ HRESIMS, the $[(\mathrm{M}-\mathrm{H})+\mathrm{AcOH}]^{-}$ion peak at $\mathrm{m} / \mathrm{z} 803.6409$, and the $[\mathrm{M}-\mathrm{H}]^{-}$deprotonated ion peak at $\mathrm{m} / \mathrm{z}$ 743.6199 in the (-)HRESIMS (Figures S39 and S40). The comparison of the molecular masses of 3 and 4 showed the difference of 2 amu between 3 and 4 . The (-)ESIMS/MS of the ion $\left[\mathrm{M}-\mathrm{H}^{-}\right.$ at $m / z 743$ contained the fragment ion peaks at $m / z 449\left[\mathrm{C}_{27} \mathrm{H}_{45} \mathrm{O}_{5}\right]^{-}$, corresponding to the loss of long-chain fatty acid, and $m / z 309\left[\mathrm{C}_{20} \mathrm{H}_{37} \mathrm{O}_{2}\right]^{-}$, corresponding to the loss of steroidal moiety. Fatty acids were identified in the same manner as for other compounds $[15,16]$. GC-MS analysis showed the existence of one major component, which was characterized as methyl $7^{\prime} Z$-eicosenoat. On the basis of these results, the structure of 4 was determined to be (25S)- $5 \alpha$-cholestane-3 $\beta, 6 \beta, 15 \alpha, 16 \beta$-tetraol-26-yl $7^{\prime}$ Z-eicosenoate. 


\subsection{In Vitro Anticancer Activity of Compounds 1-4}

\subsubsection{The Cytotoxic Activity of Compounds 1-4 against Normal and Cancer Cells}

At the first stage of biological activity evaluation, the cytotoxicity of compounds 1-4 against mouse normal epidermal JB6 Cl41 cells, human breast cancer MDA-MB-231 cells, and colorectal carcinoma HCT 116 cells was determined by MTS assay, which is based on the cleavage of (3-(4,5-dimethylthiazol-2-yl)-5-(3-carboxymethoxyphenyl)-2-(4-sulfophenyl)-2H-tetrazolium) (MTS reagent) into a formazan product soluble in tissue culture medium. It was found that compounds 1-4 suppressed the cell viability by less than $15 \%$ at $100 \mu \mathrm{M}$ after $24 \mathrm{~h}$ of incubation (Figure S48).

Many natural compounds do not possess direct cytotoxic activity but are able to suppress cell viability time-dependently [17]. That is why the cytostatic activity of compounds $\mathbf{1}-\mathbf{4}$ was determined against JB6 C141, MDA-MB-231, and HCT 116 cell lines for 24, 48, and $72 \mathrm{~h}$. After $72 \mathrm{~h}$ cell incubation, it was shown that the concentrations of compounds 1,2, and 3 that caused $50 \%$ inhibition of growth ( $\mathrm{IC}_{50}$ ) of JB6 Cl41 cells were 81, 40, and $79 \mu \mathrm{M}$, respectively (Figure 3A); for MDA-MB-231 cells, $\mathrm{IC}_{50}$ concentrations of compounds $\mathbf{1}, \mathbf{2}$, and 3 were 74,33 , and $73 \mu \mathrm{M}$, respectively; for HCT 116 cells, $\mathrm{IC}_{50}$ concentrations of compounds 1, 2, and 3 were 73, 31, and $71 \mu \mathrm{M}$, respectively (Figure 3). The cytostatic effect of $\mathbf{2}$ was more prominent in colorectal carcinoma HCT 116 cells.
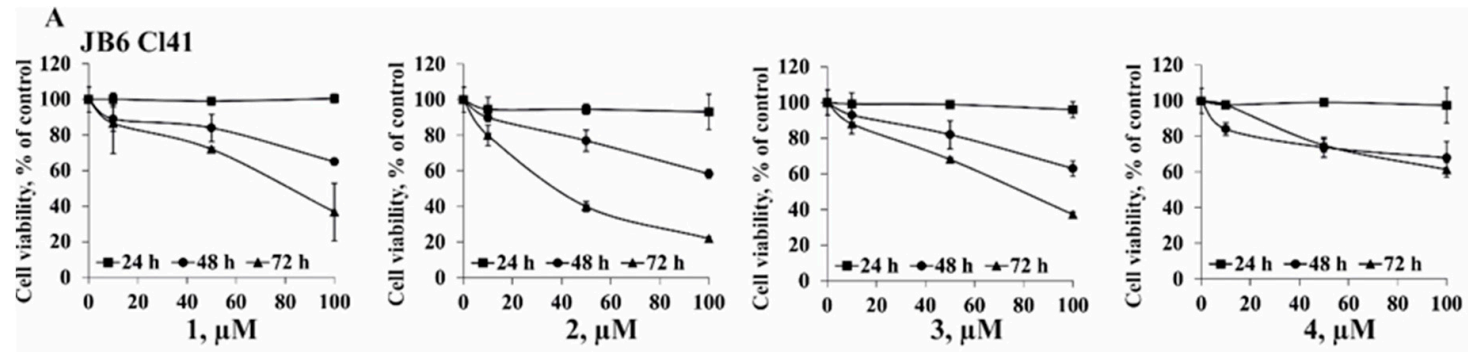

B
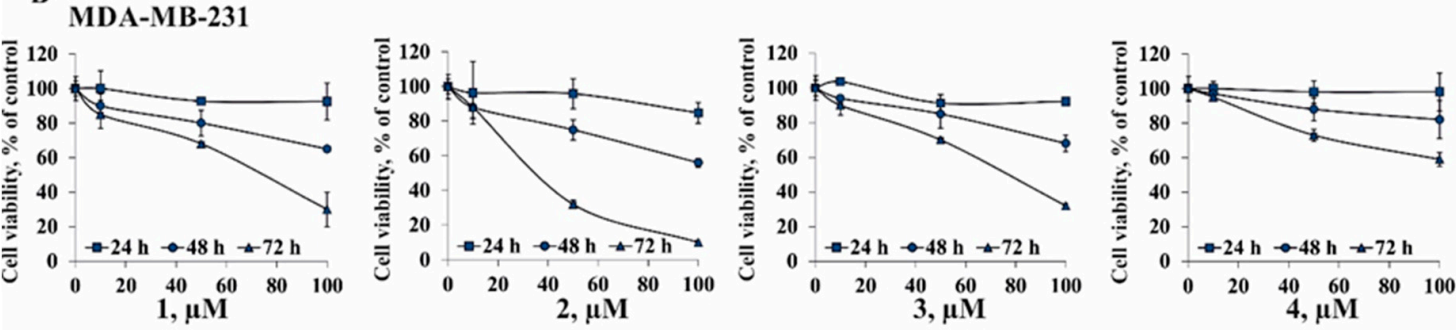

C
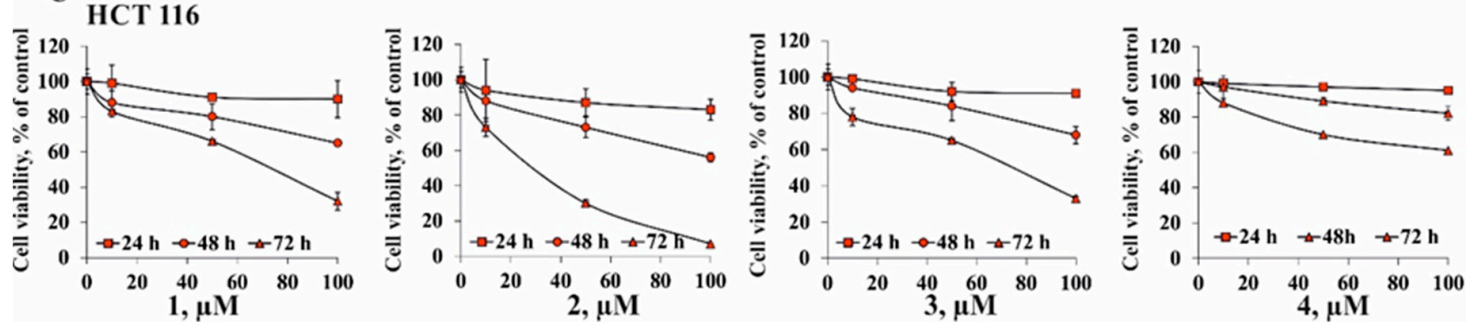

Figure 3. The cytostatic activity of compounds 1-4 against normal epidermal JB6 Cl41 cells, breast cancer MDA-MB-231 cells, and colorectal carcinoma HCT 116 cells. (A) JB6 Cl41, (B) MDA-MB-231, or (C) HCT 116 cells were treated with compounds 1-4 at concentrations of 1-100 $\mu \mathrm{M}$ for 24, 48, and $72 \mathrm{~h}$. Cell viability was estimated using the MTS assay. Data are represented as the mean \pm SD as determined from triplicate experiments.

It should be noted that investigated compounds did not exert a selective effect on cancer cells, because the viability of normal cells was suppressed as well. Therefore we checked the assumption whether compounds 1-4 were able to influence the process of carcinogenesis (colony formation, growth, and migration of cancer cells) at the non-toxic concentration of $20 \mu \mathrm{M}$. 
2.2.2. The Effect of Compounds 1-4 on the Colony Formation and Growth of Human Cancer Cells

The formation of colonies is one of the most stringent characteristics for malignant transformation in cells [18]. In the present study the soft agar assay was used to investigate the effect of compounds 1-4 on capability of cancer cells to form colonies.

It was found that compounds 1, 2, 3, and 4 inhibited colony formation in MDA-MB-231 cells by $17 \%, 26 \%, 15 \%$, and $10 \%$, respectively. Meanwhile, compounds 1, 2, 3, and 4 inhibited colony formation in HCT 116 cells by $20 \%, 27 \%, 18 \%$, and $16 \%$, respectively. Compound 2 possessed comparable inhibitory activity against colony formation of both types of cancer cell lines (Figure 4).

A

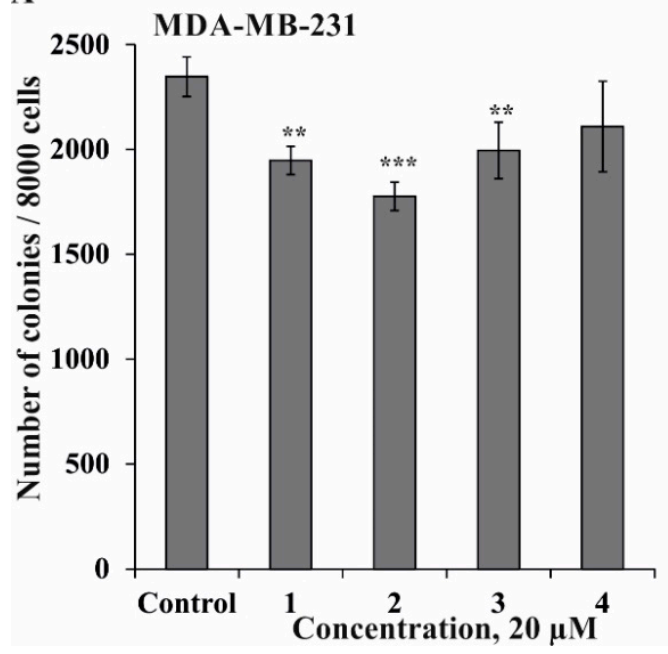

B

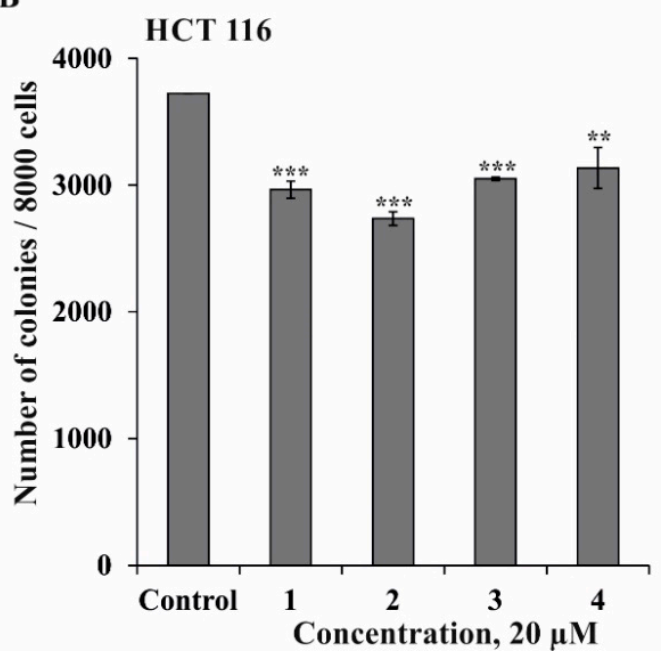

Figure 4. The effect of compounds 1-4 on colony formation in human cancer cells. MDA-MB-231 (A) or HCT 116 cells $(\mathbf{B})\left(2.4 \times 10^{4}\right)$ were treated with or without investigated compounds $(20 \mu \mathrm{M})$ and applied onto $0.3 \%$ Basal Medium Eagle (BME) agar containing 10\% FBS, $2 \mathrm{mM} \mathrm{L-glutamine,} \mathrm{and} 25 \mathrm{\mu g} / \mathrm{mL}$ gentamicin. After 14 days of incubation, the number of colonies was evaluated under a microscope with the aid of the ImageJ software program. Results are expressed as the mean \pm standard deviation (SD). The asterisks $\left.{ }^{* *} p<0.01, * * * p 0.001\right)$ indicate a significant decrease in colony number of cancer cells treated by compounds compared with control.

\subsubsection{The Effect of Compounds 1-4 on Migration of Human Cancer Cells}

The metastasis process is proven to be the leading cause of cancer-related death. Metastasis is a multistep process that includes migration and invasion of cancer cells, hallmarks of malignancy [19]. Therefore, we investigated the ability of compounds 1-4 to inhibit the migration of breast cancer MDA-MB-231 cells and colorectal carcinoma HCT 116 cells with high metastatic potential. It was demonstrated that compounds 1 and $\mathbf{2}$ (at concentration $20 \mu \mathrm{M}$ ) were able to prevent migration of MDA-MB-231 cells by $42 \%$ and 50\%, respectively, compared to control after $48 \mathrm{~h}$ of incubation (Figure 5). Compounds 3 and 4 possessed moderate inhibitory activity against migration of MDA-MB-231 cells. On the other hand, the migration of HCT 116 cells was almost completely inhibited by compound 2 (with the percentage of migration prevention being 73\%). Compounds 1, 3, and 4 prevented HCT 116 cell migration by $36 \%, 30 \%$, and $24 \%$, respectively (Figure 5). Compounds 1, 3, and 4 prevented HCT 116 cell migration by $36 \%, 30 \%$, and $24 \%$, respectively (Figure 5 ). 


\section{MDA-MB-231}

$\mathbf{0 ~ h}$

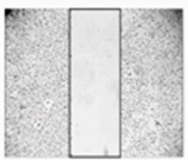

$48 \mathrm{~h}$

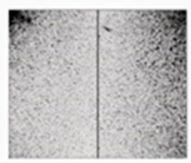

Control

C

\section{HCT 116}

o h

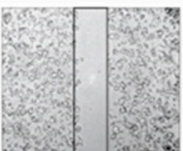

$48 \mathrm{~h}$

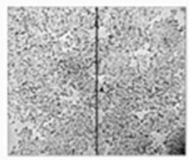

Control
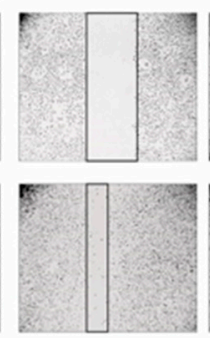

1
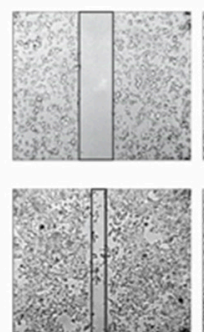

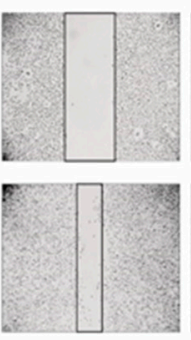

2

Concentration, $20 \mu \mathrm{M}$

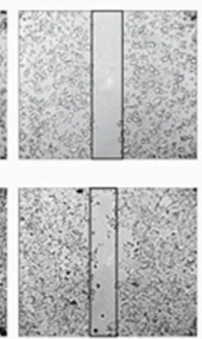

2

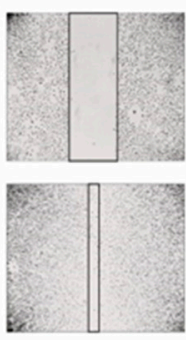

3

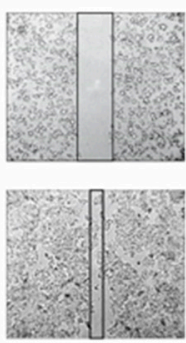

3

Concentration, $20 \mu \mathrm{M}$
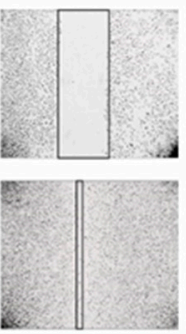

4

B

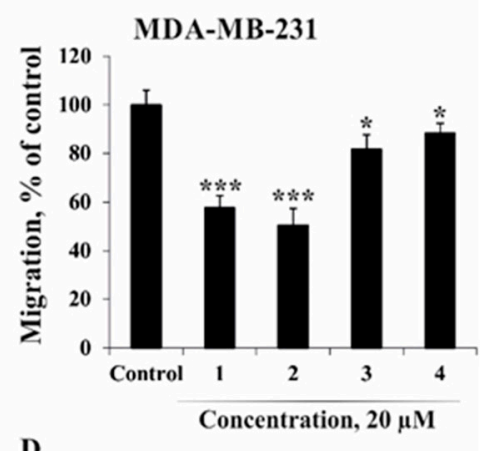

D
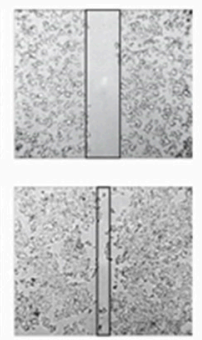

4

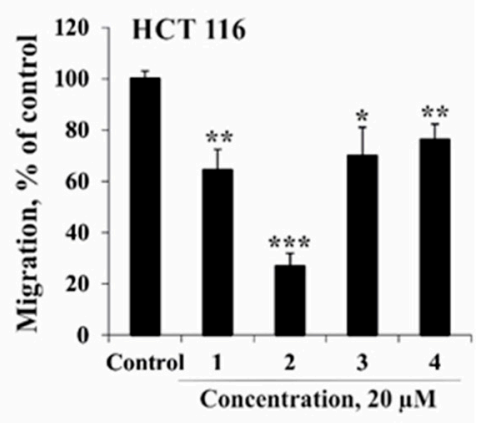

Figure 5. The effect of compounds 1-4 on migration of human cancer cells. MDA-MB-231 (A,B) and HCT 116 (C,D) cells migration distance was estimated by measuring the width of the wound and expressed as a percentage of each control for the mean of wound closure area. All experiments were repeated at least three times in each group ( $\mathrm{n}=18$ for control and each compound, $\mathrm{n}$-quantity of photos). The magnification of representative photos is $\times 10$. Results are expressed as the mean \pm standard deviation (SD). The asterisks $\left({ }^{*} p<0.05,{ }^{* *} p<0.01,{ }^{* * *} p<0.001\right)$ indicate a significant decrease in migration of cells treated with compounds compared with the control.

\section{Materials and Methods}

\subsection{General Procedures}

Optical rotations were determined on a PerkinElmer 343 polarimeter (Waltham, MA, USA). IR spectra were determined on a Bruker OPUS Vector-22 infrared spectrophotometer in $\mathrm{CDCl}_{3}$. The ${ }^{1} \mathrm{H}$ - and ${ }^{13} \mathrm{C}-\mathrm{NMR}$ spectra were recorded on Bruker Avance III 700 spectrometer (Bruker, Germany) at 700.13 and $176.04 \mathrm{MHz}$, respectively, and chemical shifts were referenced to the corresponding residual solvent signal $\left(\delta_{\mathrm{H}} 3.30 / \delta_{\mathrm{C}} 49.0\right.$ for $\left.\mathrm{CD}_{3} \mathrm{OD}\right)$. The HRESIMS spectra were recorded on a Bruker Impact II Q-TOF mass spectrometer (Bruker, Germany); the samples were dissolved in $\mathrm{MeOH}$ (c $0.001 \mathrm{mg} / \mathrm{mL}$ ). HPLC separations were carried out on an Agilent 1100 Series chromatograph (Agilent Technologies, Santa Clara, CA, USA) equipped with a differential refractometer; Discovery C18 (5 $\mu \mathrm{m}, 250 \times 10 \mathrm{~mm}$, Supelco, Bellefonte, PA, USA) column was used. GC and GC-MS analyses were performed on a GC 2010 chromatograph with a flame ionization detector and a gas chromatograph couple to a mass spectrometer GCMS-QP5050, both from Shimadzu (Japan). Fused silica capillary columns Supelcowax 10 and MDN-5S (both columns $30 \mathrm{~m}, 0.25 \mathrm{~mm}$ ID, $0.25 \mu \mathrm{m}$ film, Supelco, PA, USA) were used in the apparatus. Low-pressure liquid column chromatography was carried out with the Si gel KSK (50-160 $\mu$ m, Sorbpolimer, Krasnodar, Russia). Sorbfil Si gel plates $(4.5 \times 6.0 \mathrm{~cm}, 5-17 \mu \mathrm{m}$, Sorbpolimer, Krasnodar, Russia) were used for thin-layer chromatography.

\subsection{Animal Material}

Specimens of Ceramaster patagonicus Sladen, 1889 (order Valvatida, family Goniasteridae), were collected at a depth of 150-300 $\mathrm{m}$ in the Sea of Okhotsk near Iturup Island during 42nd 
scientific cruise of the research vessel Akademik Oparin, in August 2012. Species identification was carried out by B. B. Grebnev (G. B. Elyakov Pacific Institute of Bioorganic Chemistry FEB RAS, Vladivostok, Russia). A voucher specimen (No. 042-67) is on deposit at the marine specimen collection of the G. B. Elyakov Pacific Institute of Bioorganic Chemistry FEB RAS, Vladivostok, Russia.

\subsection{Extraction and Isolation}

The fresh animals of $C$. patagonicus ( $3 \mathrm{~kg}$, crude weight) were chopped into small pieces and extracted with $\mathrm{CHCl}_{3}: \mathrm{MeOH}$ (2:1) followed by further extraction with $\mathrm{CHCl}_{3}: \mathrm{MeOH}$ (1:1) and $\mathrm{EtOH}$. The combined extracts were concentrated in vacuo to give a residue of $159.5 \mathrm{~g}$. This residue was partitioned between $\mathrm{H}_{2} \mathrm{O}(1.5 \mathrm{~L})$ and AcOEt:BuOH (2:1) $(4.5 \mathrm{~L})$, and the organic layer was concentrated in vacuo to give the less polar fraction $(51.5 \mathrm{~g})$, which was washed with cold acetone $(1 \mathrm{~L})$. The acetone-soluble part $(28.5 \mathrm{~g})$ was chromatographed over a silica gel column $(19 \times 4.5 \mathrm{~cm})$ using $\mathrm{CHCl}_{3}, \mathrm{CHCl}_{3}: \mathrm{MeOH}(97: 3)$, and $\mathrm{CHCl}_{3}: \mathrm{MeOH}$ (9:1) to yield four fractions: 1 (932 mg), 2 (486 mg), $3(735 \mathrm{mg})$, and $4(1.04 \mathrm{~g})$. Fractions $1-4$ were further chromatographed over a Si gel column $(10 \times 4 \mathrm{~cm})$ using $n$-hexane:AcOEt:MeOH (stepwise gradient, $6: 3: 0.1 \rightarrow 6: 3: 0.7, v / v / v$ ) to yield six subfractions: 21 (123 mg), 31 (475 mg), 32 (231 mg), 41 (55 mg), $42(212 \mathrm{mg})$, and 43 (570 mg), which were then analyzed by TLC in the eluent system $\mathrm{CHCl}_{3}: \mathrm{MeOH}: \mathrm{H}_{2} \mathrm{O}(8: 1: 0.1, v / v / v)$. Subfractions 21-43 mainly contained the ceramides, cerebrosides, admixtures of pigments, and concomitant other lipids. HPLC separation of subfraction $32(231 \mathrm{mg})$ on a Diasfer-110-C18 column $(2.5 \mathrm{~mL} / \mathrm{min})$ with $\mathrm{MeOH}$ as an eluent yielded pure 1 (4.4 mg, $\left.R_{t} 42.3 \mathrm{~min}\right), 2$ ( $\left.2.5 \mathrm{mg}, R_{t} 51.9 \mathrm{~min}\right), 3\left(3.9 \mathrm{mg}, R_{t} 55.7 \mathrm{~min}\right)$, and 4 (2.9 $\left.\mathrm{mg}, \mathrm{R}_{\mathrm{t}} 72.5 \mathrm{~min}\right)$.

\subsection{Compound Characterization Data}

(25S)-5 $\alpha$-Cholestane-3 $\beta, 6 \beta, 15 \alpha, 16 \beta$-tetraol-26-yl 5'Z,11'Z-octadecadienoate (1): Amorphous powder; $[\alpha]_{\mathrm{D}}{ }^{25}:+8.1(c 0.44, \mathrm{MeOH})$; IR $\left(\mathrm{CDCl}_{3}\right) v_{\max } 3504,2929,2856,1723,1602,1459,1379,1216$, $1042 \mathrm{~cm}^{-1} ;(+)$ HRESIMS m/z $737.5695[\mathrm{M}+\mathrm{Na}]^{+}$(calcd for $\left.\mathrm{C}_{45} \mathrm{H}_{78} \mathrm{O}_{6} \mathrm{Na}, 737.5695\right) ;(-)$ HRESIMS $\mathrm{m} / \mathrm{z}$ $773.5934\left[(\mathrm{M}-\mathrm{H})+\mathrm{AcOH}^{-}\right.$(calcd for $\left.\mathrm{C}_{47} \mathrm{H}_{81} \mathrm{O}_{8}, 773.5937\right), 713.5726[\mathrm{M}-\mathrm{H}]^{-}$(calcd for $\mathrm{C}_{45} \mathrm{H}_{77} \mathrm{O}_{6}$, 713.5729); (-)ESIMS/MS of the ion at $m / z$ 713: $m / z 449\left[\mathrm{C}_{27} \mathrm{H}_{45} \mathrm{O}_{5}\right]^{-}, 279\left[\mathrm{C}_{18} \mathrm{H}_{31} \mathrm{O}_{2}\right]^{-} ;{ }^{1} \mathrm{H}-$ and ${ }^{13} \mathrm{C}-\mathrm{NMR}$ data, see Tables 1 and 2.

(25S)- $5 \alpha$-Cholestane-3 $\beta, 6 \beta, 15 \alpha, 16 \beta$-tetraol-26-yl 11'Z-octadecenoate (2): Amorphous powder; $[\alpha]_{\mathrm{D}}^{25}:+14.1(c 0.25, \mathrm{MeOH}) ; \mathrm{IR}\left(\mathrm{CDCl}_{3}\right) v_{\max } 3504,2929,2856,1723,1602,1465,1379,1260,1216$, $1043 \mathrm{~cm}^{-1} ;(+)$ HRESIMS $\mathrm{m} / \mathrm{z} 739.5852[\mathrm{M}+\mathrm{Na}]^{+}$(calcd for $\left.\mathrm{C}_{45} \mathrm{H}_{80} \mathrm{O}_{6} \mathrm{Na}, 739.5847\right) ;(-)$ HRESIMS $\mathrm{m} / \mathrm{z}$ $775.6096[(\mathrm{M}-\mathrm{H})+\mathrm{AcOH}]^{-}$(calcd for $\left.\mathrm{C}_{47} \mathrm{H}_{83} \mathrm{O}_{8}, 775.6093\right) ; \mathrm{m} / \mathrm{z} 715.5889[\mathrm{M}-\mathrm{H}]^{-}$(calcd for $\mathrm{C}_{45} \mathrm{H}_{79} \mathrm{O}_{6}$, 715.5882); (-)ESIMS/MS of the ion at $m / z 715: m / z 449\left[\mathrm{C}_{27} \mathrm{H}_{45} \mathrm{O}_{5}\right]^{-}, 281\left[\mathrm{C}_{18} \mathrm{H}_{33} \mathrm{O}_{2}\right]^{-} ;{ }^{1} \mathrm{H}-$ and ${ }^{13} \mathrm{C}-\mathrm{NMR}$ data, see Tables 1 and 2.

(25S)-5 $\alpha$-Cholestane-3 $\beta, 6 \beta, 15 \alpha, 16 \beta$-tetraol-26-yl 5' Z,11'Z-eicosadienoate (3): Amorphous powder; $[\alpha]_{\mathrm{D}}{ }^{25}:+9.5(c 0.39, \mathrm{MeOH}) ; \mathrm{IR}\left(\mathrm{CDCl}_{3}\right) v_{\max } 3510,2929,2856,1723,1603,1493,1465,1379,1365$, 1248, 1216, 1189, 1080, $1042 \mathrm{~cm}^{-1} ;(+)$ HRESIMS $m / z 765.6008[\mathrm{M}+\mathrm{Na}]^{+}$(calcd for $\mathrm{C}_{47} \mathrm{H}_{82} \mathrm{O}_{6} \mathrm{Na}$, 765.6004); (-)HRESIMS $m / z$ 801.6254 [(M - H) $+\mathrm{AcOH}]^{-}$(calcd for $\mathrm{C}_{49} \mathrm{H}_{85} \mathrm{O}_{8}, 801.6250$ ); $/ \mathrm{z} 741.6044$ [M - H] $]^{-}$(calcd for $\left.\mathrm{C}_{47} \mathrm{H}_{81} \mathrm{O}_{6}, 741.6039\right)$; (-)ESIMS/MS of the ion at $m / z 741: m / z 449\left[\mathrm{C}_{27} \mathrm{H}_{45} \mathrm{O}_{5}\right]^{-}$, $307\left[\mathrm{C}_{20} \mathrm{H}_{35} \mathrm{O}_{2}\right]^{-} ;{ }^{1} \mathrm{H}-$ and ${ }^{13} \mathrm{C}-\mathrm{NMR}$ data, see Tables 1 and 2.

(25S)-5 $\alpha$-Cholestane-3 $\beta, 6 \beta, 15 \alpha, 16 \beta$-tetraol-26-yl 7'Z-eicosenoate (4): Amorphous powder; $[\alpha]_{\mathrm{D}}{ }^{25}$ : +15.4 (c 0.29, MeOH); IR $\left(\mathrm{CDCl}_{3}\right) v_{\max } 3515,2929,2856,1723,1602,1466,1378,1261,1204,1043 \mathrm{~cm}^{-1}$; (+)HRESIMS $m / z$ 767.6157 [M + Na] ${ }^{+}$(calcd for $\mathrm{C}_{47} \mathrm{H}_{84} \mathrm{O}_{6} \mathrm{Na}$, 767.6160); (-)HRESIMS $m / z$ 803.6409 $[(\mathrm{M}-\mathrm{H})+\mathrm{AcOH}]^{-}$(calcd for $\left.\mathrm{C}_{49} \mathrm{H}_{87} \mathrm{O}_{8}, 803.6406\right) ; \mathrm{m} / z$ 743.6199 $[\mathrm{M}-\mathrm{H}]^{-}$(calcd for $\mathrm{C}_{47} \mathrm{H}_{83} \mathrm{O}_{6}$, 743.6195); (-)ESIMS/MS of the ion at $m / z$ 743: $m / z 449\left[\mathrm{C}_{27} \mathrm{H}_{45} \mathrm{O}_{5}\right]^{-}, 309\left[\mathrm{C}_{20} \mathrm{H}_{37} \mathrm{O}_{2}\right]^{-} ;{ }^{1} \mathrm{H}-$ and ${ }^{13} \mathrm{C}-\mathrm{NMR}$ data, see Tables 1 and 2. 


\subsection{Methanolysis and Preparation of 4,4-Dimethyloxazoline Derivatives of Fatty Acids}

Compounds 1-4 (1 mg) were heated with $1 \mathrm{~N} \mathrm{HCl}$ in $80 \%$ aq $\mathrm{MeOH}(1.0 \mathrm{~mL})$ at $80{ }^{\circ} \mathrm{C}$ for $4 \mathrm{~h}$. The reaction mixtures were then extracted with $n$-hexane, and the extracts were concentrated in vacuo to yield FAME-1-FAME-4. The 4,4-Dimethyloxazoline derivatives of fatty acids of compounds 1 and 4 were prepared from FAME-1 and FAME-4 according to the procedure described previously [15].

\subsection{FAME and DMOX Analysis.}

FAMEs were analyzed on Supelcowax 10 columns at $200^{\circ} \mathrm{C}$. DMOX derivatives analyzed on a nonpolar MDN-5S column, where the temperature program ranged from 200 to $260^{\circ} \mathrm{C}$ at $2{ }^{\circ} \mathrm{C} / \mathrm{min}$. Helium was used as the carrier gas at a linear velocity of $30 \mathrm{~cm} / \mathrm{s}$. Mass spectra were recorded at $70 \mathrm{eV}$. Mass spectra were compared with the NIST library and internet fatty acid mass spectra archive site.

\subsection{Bioactivity Assay}

\subsubsection{Reagents}

Phosphate buffered saline (PBS), L-glutamine, penicillin-streptomycin solution $(10,000 \mathrm{U} / \mathrm{mL}$, $10 \mu \mathrm{g} / \mathrm{mL}$ ) were from Sigma-Aldrich (St. Louis, MO, USA). MTS reagent (3-(4,5-dimethylthiazol-2-yl)5-(3-carboxymethoxyphenyl)-2-(4-sulfophenyl)-2H-tetrazolium) was purchased from Promega (Madison, WI, USA). The Basal Medium Eagle (BME), Minimum Essential Medium Eagle (MEM), Dulbecco's Modified Eagle's Medium (DMEM), McCoy's 5A Modified Medium (McCoy's 5A), trypsin, fetal bovine serum (FBS), and agar were purchased from Thermo Fisher Scientific (Waltham, MA, USA).

\subsubsection{Cell Cultures}

Mouse epidermal JB6 Cl41 (ATCC No. CRL-2010), human breast cancer MDA-MB-231 (ATCC HTB-26), and colorectal carcinoma HCT 116 (ATCC CCL-247) cell lines were cultured in MEM, DMEM, and McCoy's 5A medium supplemented with 5\%, 10\%, and 10\% FBS, respectively, and $1 \%$ penicillin-streptomycin solution. The cell cultures were maintained at $37^{\circ} \mathrm{C}$ in humidified atmosphere containing $5 \% \mathrm{CO}_{2}$.

\subsubsection{Compounds Preparation}

Compounds 1-4 were dissolved in DMSO to prepare stock concentrations of $20 \mathrm{mM}$. Cells were treated with serially diluted compounds (culture medium used as diluent) to give the intended final concentrations $(1,10,20,50$, and $100 \mu \mathrm{M})$. Solvent tolerance testing up to $0.5 \%$ of DMSO in control cells under identical conditions confirmed that the viability of all cell lines was unaffected. The vehicle control was the cells treated with equivalent volume of DMSO for all presented experiments.

\subsubsection{Cell Viability Assay}

To determine the cytotoxicity of compounds 1-4, JB6 Cl41, MDA-MB-231, and HCT 116 cells $\left(1.0 \times 10^{4}\right)$ were seeded in $200 \mu \mathrm{L}$ of complete MEM/5\% FBS, DMEM $/ 10 \%$ FBS, and McCoy's $5 \mathrm{~A} / 10 \%$ FBS medium, respectively, and incubated for $24 \mathrm{~h}$ at $37^{\circ} \mathrm{C}$ in $5 \% \mathrm{CO}_{2}$ incubator. The attached cells were incubated with fresh medium containing various concentrations of 1-4 $(0-100 \mu \mathrm{M})$ or equivalent volume of DMSO (control) for additional $24 \mathrm{~h}$. Subsequently, the cells were incubated with $15 \mu \mathrm{L}$ MTS reagent for $3 \mathrm{~h}$, and the absorbance of each well was measured at 490/630 nm using Power Wave XS microplate reader (BioTek, Winooski, VT, USA). All experimental conditions were assessed in triplicate.

To determine the effect of compounds 1-4 on cell proliferation, the tested cell lines $\left(8 \times 10^{3}\right.$ cells/200 $\left.\mu \mathrm{L}\right)$ were treated with tested compounds at concentrations of $1,10,50$, and $100 \mu \mathrm{M}$ or equivalent volume of DMSO (control) and incubated for additional 24,48 , and $72 \mathrm{~h}$ at $37^{\circ} \mathrm{C}$ in $5 \% \mathrm{CO}_{2}$. MTS reagent $(20 \mu \mathrm{L})$ was added to each well, and the cells were incubated for additional $3 \mathrm{~h}$ in $5 \% \mathrm{CO}_{2}$ 
incubator. Absorbance was measured at $490 / 630 \mathrm{~nm}$ by microplate reader. All experimental conditions were assessed in triplicate.

\subsubsection{Soft Agar Assay}

To estimate the effects of 1-4 on colony formation (phenotype expression), MDA-MB-231 and HCT 116 cells $\left(2.4 \times 10^{4}\right.$ cells $\left./ 200 \mu \mathrm{L}\right)$ were treated equivalent volume of DMSO (control) or with compounds 1-4 (20 $\mu \mathrm{M})$ in $1 \mathrm{~mL}$ of $0.3 \%$ Basal Medium Eagle (BME) agar containing 10\% FBS, $2 \mathrm{mM}$ L-glutamine, and $25 \mu \mathrm{g} / \mathrm{mL}$ gentamicin. The cultures were maintained in a $37{ }^{\circ} \mathrm{C}, 5 \% \mathrm{CO}_{2}$ incubator for 14 days, and the cell colonies were scored using a Motic AE 20 microscope (XiangAn, Xiamen, China) and ImageJ software bundled with 64-bit Java 1.8.0_112 (NIH, Bethesda, MD, USA).

\subsubsection{Wound Healing Assay}

MDA-MB-231 and HCT 116 cells $\left(3 \times 10^{5}\right.$ cells $\left./ \mathrm{mL}\right)$ were seeded into six-well plates and grown to $80 \%$ confluence for $24 \mathrm{~h}$. After removing the culture medium, the cells' monolayer was scraped with a $200 \mu \mathrm{L}$ sterile pipette tip to create a straight scratch. Then, MDA-MB-231 and HCT 116 cells were treated with equivalent volume of DMSO (control) or 1-4 at concentration of $20 \mu \mathrm{M}$ and incubated for $48 \mathrm{~h}$. All experiments were conducted in triplicate for each group. For the image analysis, cell migration into the wound area was photographed at the stages of 0 and $48 \mathrm{~h}$ using a Motic AE 20 microscope and ImageJ software. The cell migration distance was estimated by measuring the width of the wound and expressed as a percentage of each control for the mean wound closure area.

\subsubsection{Statistical Analysis}

All assays were performed using least three independent experiments. Results are expressed as the mean \pm standard deviation (SD). Student's $t$-test was used to evaluate the data with the following significance levels: ${ }^{*} p<0.05,{ }^{* *} p<0.01,{ }^{* * *} p<0.001$.

\section{Conclusions}

Four new steroidal conjugates, esters of polyhydroxysteroids with long-chain fatty acids (1-4), were isolated from the Far Eastern starfish C. patagonicus. Unusual compounds 1-4 contain the same $5 \alpha$-cholestane-3 $3,6 \beta, 15 \alpha, 16 \beta, 26$-pentahydroxysteroidal moiety and differ from each other in fatty acid residues: $5^{\prime} Z, 11^{\prime} Z$-octadecadienoic (1), 11'Z-octadecenoic (2), $5^{\prime} Z, 11^{\prime} Z$-eicosadienoic (3), and $7^{\prime} Z$-eicosenoic (4) acid units. It should be noted that the isolated conjugates $1-4$ have a shared steroidal part and differ in the composition of fatty acid residues. The question arises about the biological role of the extracted compounds. Previously we have been found that starfish polyhydroxylated steroids were presented mainly in digestive organs of starfishes during the whole year, and their maximum concentration coincided with periods of active nutrition of these animals [20,21]. Recently, we confirmed the digestive function of polyhydroxysteroids, when studying the distribution of polar steroids in various organs of the starfish Lethasterias fusca using the nLC/CSI-QTOF-MS method, and the highest level of polar steroids was found in the stomach and the pyloric caeca [22] Thus, it can be assumed that polyhydroxysteroids can bind food fatty acids and participate in their transport to peripheral tissues, like cholesterol of vertebrates and humans. This assumption is partially confirmed by the heterogeneous composition of fatty acids in compounds 1-4, since saturated, mono- and di-unsaturated C16, C18, and C20 fatty acids were found together with the main components. The isolation of conjugates of polyhydroxysteroids and fatty acids from the Far Eastern starfish C. patagonicus is a very interesting finding; to the best of our knowledge, hypotheses about the possible transport role of polyhydroxysteroids have not been put forward. At the same time, this assumption requires confirmation by experimental data.

We have expanded the data on the biological activity of these unique compounds-conjugates of polyhydroxysteroids and fatty acids. It was shown that tested compounds $\mathbf{1 - 4}$ possessed cytostatic activity against normal JB6 Cl41 cells and cancer MDA-MB-231 and HCT 116 cell lines. The compounds 
1-4 at low concentration of $20 \mu \mathrm{M}$ were able to suppress the colony formation in MDA-MB-231 and HCT 116 cells and almost completely prevent the migration of human breast and colorectal cancer cells. It should be noted that compound 2 was the most active in all experiments performed. This is likely due to the presence of an $11^{\prime} Z$-octadecenoic acid residue in its structure. Unfortunately, the lack of selectivity of the investigated compounds against normal and cancer cells was determined, which can be limit their possible practical use. However, the identification of these novel compounds and an initial characterization of their biological activity, performed for the first time, might be helpful to other researchers working on the development of conjugates of polyhydroxysteroids and fatty acids.

Supplementary Materials: The following are available online at http://www.mdpi.com/1660-3397/18/5/260/s1. Copies (+)HRESIMS (Figures S1, S21, S30, and S39), (-)HRESIMS (Figures S2, S22, S31, and S40), (-)ESIMS/MS (Figures S3, S23, S32, and S41), ${ }^{1} \mathrm{H}-\mathrm{NMR}$ (Figures S4-S8, S24, S33, and S42), ${ }^{13}$ C-NMR (Figures S9-S12, S25, S34, and S43), COSY (Figures S13, S14, S26, S35, and S44), HSQC (Figures S15, S16, S27, S36, and S45), HMBC (Figures S17, S18, S28, S37, and S46), and ROESY (Figures S19, S20, S29, S38, and S47) spectra of compounds 1, 2, 3, and 4 , respectively.

Author Contributions: T.V.M., the isolation and structure elucidation of metabolites, and manuscript preparation; A.A.K. and N.V.I., the analysis of the compounds and manuscript editing; V.M.Z. and I.P.K., the isolation and structure elucidation of metabolites; A.I.K., the acquisition and interpretation of NMR spectra; V.I.S., the analysis and identification of fatty acids; O.S.M., the determination of the metabolites' effects on the viability, proliferation, colony formation, and migration of tested cells; R.S.P., the acquisition and interpretation of mass spectra. All authors have read and agreed to the published version of the manuscript.

Funding: The isolation and establishment of chemical structures were partially supported by Grant No. 20-03-00014 from the RFBR (Russian Foundation for Basic Research). The study on the anticancer activity of starfish metabolites was supported by Grant No. 18-74-10028 from the RSF (Russian Science Foundation).

Acknowledgments: The study was carried out on the equipment of the Collective Facilities Center "The Far Eastern Center for Structural Molecular Research (NMR/MS) of PIBOC FEB RAS". We are grateful to B.B. Grebnev (G.B. Elyakov Pacific Institute of Bioorganic Chemistry FEB RAS, Vladivostok, Russia) for species identification of the starfish and V.A. Stonik for the manuscript editing.

Conflicts of Interest: The authors declare no conflict of interest.

\section{References}

1. Gomes, A.R.; Freitas, A.C.; Rocha-Santos, T.A.P.; Duarte, A.C. Bioactive compounds derived from echinoderms. RSC Adv. 2014, 4, 29365-29382. [CrossRef]

2. Minale, L.; Riccio, R.; Zollo, F. Steroidal oligoglycosides and polyhydroxysteroids from Echinoderms. Fortschr. Chem. Org. Nat. 1993, 62, 75-308.

3. Stonik, V.A. Marine polar steroids. Russ. Chem. Rev. 2001, 70, 673-715. [CrossRef]

4. Iorizzi, M.; De Marino, S.; Zollo, F. Steroidal oligoglycosides from the Asteroidea. Curr. Org. Chem. 2001, 5 , 951-973. [CrossRef]

5. Stonik, V.A.; Ivanchina, N.V.; Kicha, A.A. New polar steroids from starfish. Nat. Prod. Commun. 2008, 3, 1587-1610. [CrossRef]

6. Dong, G.; Xu, T.H.; Yang, B.; Lin, X.P.; Zhou, X.F.; Yang, X.W.; Liu, Y.H. Chemical constituents and bioactivities of starfish. Chem. Biodivers. 2011, 8, 740-791. [CrossRef]

7. Ivanchina, N.V.; Kicha, A.A.; Stonik, V.A. Steroid glycosides from marine organisms. Steroids 2011, 76, 425-454. [CrossRef]

8. Ivanchina, N.V.; Kicha, A.A.; Malyarenko, T.V.; Stonik, V.A. Advances in Natural Products Discovery; Gomes, A.R., Rocha-Santos, T., Duarte, A., Eds.; Nova Science Publishers: Hauppauge, NY, USA, 2017; Volume 6, pp. 191-224.

9. Xia, J.M.; Miao, Z.; Xie, C.L.; Zhang, J.W.; Yang, X.W. Chemical constituents and bioactivities of starfishes: An update. Chem. Biodivers. 2020, 17, e1900638. [CrossRef]

10. Kicha, A.A.; Ivanchina, N.V.; Malyarenko, T.V.; Kalinovsky, A.I.; Popov, R.S.; Stonik, V.A. Six new polyhydroxylated steroid taurine conjugates, microdiscusols A-F, from the Arctic starfish Asterias microdiscus. Steroids 2019, 150, 108458. [CrossRef] 
11. Peng, Y.; Zheng, J.; Huang, R.; Wang, Y.; Xu, T.; Zhou, X.; Liu, Q.; Zeng, F.; Ju, H.; Yang, X.; et al. Polyhydroxy steroids and saponins from China sea starfish Asterina pectinifera and their biological activities. Chem. Pharm. Bull. 2010, 58, 856-858. [CrossRef]

12. Wang, W.; Hong, J.; Lee, C.-O.; Im, K.S.; Choi, J.S.; Jung, J.H. Cytotoxic sterols and saponins from the starfish Certonardoa semiregularis. J. Nat. Prod. 2004, 67, 584-591. [CrossRef] [PubMed]

13. Minale, L.; Pizza, C.; Zollo, F. $5 \alpha$-cholestane- $3 \beta, 6 \beta, 15 \alpha, 16 \beta, 26$-pentaol: A polyhydroxylated sterol from the starfish Hacelia attenuata. Tetrahedron Lett. 1982, 23, 1841-1844. [CrossRef]

14. Kicha, A.A.; Kalinovsky, A.I.; Stonik, V.A. New polyhydroxysteroids and steroid glycosides from the Far East starfish Ceramaster patagonicus. Russ. Chem. Bull. 1997, 46, 186-191. [CrossRef]

15. Svetashev, V.I. Mild method for preparation of 4,4-dimethyloxazoline derivatives of polyunsaturated fatty acids for GC-MS. Lipids 2011, 46, 463-467. [CrossRef]

16. Stransky, K.; Jursik, T.; Vitek, A. Standard equivalent chain length values of monoenic and polyenic (methylene interrupted) fatty acids. J. High Resolut. Chromatogr. 1997, 20, 143-158. [CrossRef]

17. Ling, T.; Lang, W.H.; Maier, J.; Centurion, M.Q.; Rivas, F. Cytostatic and cytotoxic natural products against cancer cell models. Molecules 2019, 24, 2012. [CrossRef]

18. Borowicz, S.; Van Scoyk, M.; Avasarala, S. The soft agar colony formation assay. J. Vis. Exp. 2014, 92, e51998. [CrossRef]

19. Tahtamouni, L.; Ahram, M.; Koblinski, J.; Rolfo, C. Molecular regulation of cancer cell migration, invasion, and metastasis. Anal. Cell. Pathol. 2019, 2019, 1356508. [CrossRef]

20. Kicha, A.A.; Ivanchina, N.V.; Gorshkova, I.A.; Ponomarenko, L.P.; Likhatskaya, G.N.; Stonik, V.A. The distribution of free sterols, polyhydroxysteroids and steroid glycosides in various body components of the starfish Patiria (=Asterina) pectinifera. Comp. Biochem. Physiol. 2001, 128, 43-52. [CrossRef]

21. Kicha, A.A.; Ivanchina, N.V.; Stonik, V.A. Seasonal variations in the levels of polyhydroxysteroids and related glycosides in the digestive tissues of the starfish Patiria (=Asterina) pectinifera. Comp. Biochem. Physiol. 2003, 136, 897-903. [CrossRef]

22. Popov, R.S.; Ivanchina, N.V.; Kicha, A.A.; Malyarenko, T.V.; Grebnev, B.B.; Stonik, V.A.; Dmitrenok, P.S. The distribution of asterosaponins, polyhydroxysteroids and related glycosides in different body components of the Far Eastern starfish Lethasterias fusca. Mar. Drugs 2019, 17, 523. [CrossRef] [PubMed]

Sample Availability: Samples of all compounds in the manuscripts are available from the authors.

(C) 2020 by the authors. Licensee MDPI, Basel, Switzerland. This article is an open access article distributed under the terms and conditions of the Creative Commons Attribution (CC BY) license (http://creativecommons.org/licenses/by/4.0/). 